\title{
PHOTOGRAMMETRIC SURVEY WITH FISHEYE LENS FOR THE CHARACTERIZATION OF THE LA SASSA CAVE
}

\author{
L. Alessandri ${ }^{1}$, V. Baiocchi ${ }^{2}$, S. Del Pizzo ${ }^{3}$, M. F. Rolfo, S. Troisi ${ }^{3}$ \\ ${ }^{1}$ University of Groningen, GIA, Poststraat 6, 9712ER, Groningen (The Netherlands) - 1.alessandri@ rug.nl \\ ${ }^{2}$ Sapienza University of Rome, DICEA, Via Eudossiana 18, 00184 Rome (Italy) - valerio.baiocchi@uniroma1.it \\ ${ }^{3}$ Parthenope University of Naples, Centro Direzionale Isola C4, Naples (Italy) - (salvatore.troisi, silvio.delpizzo)@uniparthenope.it \\ ${ }^{4}$ University of Tor Vergata, Department of History, Culture and Society, Via Columbia 1, 00133 Rome (Italy) - rolfo@uniroma2.it
}

\section{Commission II}

KEY WORDS: Photogrammetry, Structure from Motion, Cultural Heritage, 3D modeling, Georeferencing, Bronze Age, Pleistocene

\begin{abstract}
:
The survey of ancient cave can generally be performed by traditional topographic methods that allow also its georeferencing in a global reference frame; some difficulties may arise when there are narrow tunnels that do not consent the use of a total station or a terrestrial laser scanner. In such cases a visual-based approach can be used to produce, both the followed path and the 3D model of the hypogeal environment. A prompt photogrammetric survey has been used to reconstruct the morphology of the La Sassa Cave, situated in the municipality of Sonnino (Latina), in the lower Lazio region. In this cave, a very large quantity of Pleistocene animal bones was found, together with several fragments of Copper Age human bones and Bronze Age impasto potsherds.

The survey was carried out using a DSLR full frame camera Nikon D800E with a Nikkor $16 \mathrm{~mm}$ fisheye lens pre-calibrated. During the acquisition, several targets were measured in order to contain the deformations model. The photogrammetric model has been georeferenced using 3 GCPs positioned outside the cave entrance where a double frequency GNSS receiver has acquired data in static session mode.
\end{abstract}

\section{INTRODUCTION}

Cave environment is generally characterized by lack of light, flowing water, high humidity, limited space, and complex morphology, so its mapping is a challenging task that has traditionally been undertaken by topographic surveying methods, indeed traverse method for establishing cave survey lines is a mature and effective one (Gallay et al, 2015).

However, acquiring details about the passage walls, profiles, and cross-sections is time intensive and ultimately relies on the operator's experience at interpreting and hand drawing the trend of the cave walls between survey stations. Because of this, a cave sketch carried out by two different operators, though similar, will never be the same. It is therefore necessary to adopt a survey method which is able to provide the most detailed description of the hypogeal environment, independently from the operator's choices.

When the modeling has to be added to the mapping operations then the methods to be used must be automatic in order to prevent the possibility that important details can escape from expert analyses.

3D models created from terrestrial laser scanning (TLS) and close-range photogrammetry offer an alternative solution or at least a valuable supplement to traditional cave survey.

3D models are often both faster to produce than a sketch and even more informative. Those models can provide cross-sections anywhere, and all this information is obtained in a non-subjective manner which is unbiased and scientifically repeatable (Jordan, 2017).

TLS is now widely recognized as a mature, reliable method to scan caves. Highly accurate LIDAR systems utilize infrared remote sensors capable of scanning hundreds of thousands of points per second, in total darkness. But this technology is very expensive and problematic (or impossible) to use in confined spaces and narrow passages.
On the other hand, photogrammetry has proven remarkable robustness and versatility in many fields. A skilled person who has the appropriate knowledge of all the steps involved in the transformation of the images into a 3D models (from the acquisition of images to the plotting phase, using photogrammetric software) is all that is needed.

Advances in technology have given rise to the development of Structure from Motion (SfM) algorithms, by which the automatic recognition of common points of interest on many images is used to implement a highly redundant auto-calibrating bundle. The latter leads to the simultaneous evaluation of the external orientation parameters of the images and to the $3 \mathrm{D}$ coordinates of the same points of interest (Del Pizzo, Troisi, 2011).

Not rarely, the underground environment is also flooded and even on such occasions the close-range photogrammetry and in particular SfM algorithms have shown their complete reliability (Menna et al, 2015; Troisi et al, 2015).

SLAM (Simultaneous Localization and Mapping) techniques (Thurn et al., 2000) provide very good results in terms of speed and accuracy. Such solutions are generally based on the optimization of the classical SfM algorithms (Mouragnon et al., 2009). The recent approaches are able to integrate several instruments, such as range cameras or laser scanning (Biber et al., 2004; Cole et al., 2006). The main goal of SLAM is to provide the mapping of an environment in real-time.

The use of fisheye lenses is particularly recommended when the environment which has to be surveyed is mainly developed in length and the other two dimensions are very narrow, for example in tunnels (Troisi et al, 2017;Perfetti et al, 2017)

While a camera equipped with a fisheye lens inevitably creates more distortion than a conventional camera with a standard lens, it also allows simultaneous capture of all the surrounding environment with considerable overlap between the photos.

A photogrammetric survey carried out with a camera equipped with a standard lens produces very accurate $3 \mathrm{D}$ models but 
requires many images to ensure an adequate overlap for the limited field of view (FOV) of the standard lens. Vice versa, the FOV is very large if the camera is equipped with a fisheye lens and much less images are necessary: every fisheye image provides much more usable data than a perspective photograph.

\section{SURVEY SETUP}

\subsection{Site description and issues}

La Sassa cave (National Cave Cadastre: La 2001) is located on the left banks of the La Sassa river, in the municipality of Sonnino (WGS84, UTM 33T, 352627E, 4587452N, figure 1). In 2014, its entrance was identified by a team of speleologists from the Gruppo Grotte Castelli Romani and Speleo Club Roma (Alessandri and Rolfo, 2015).

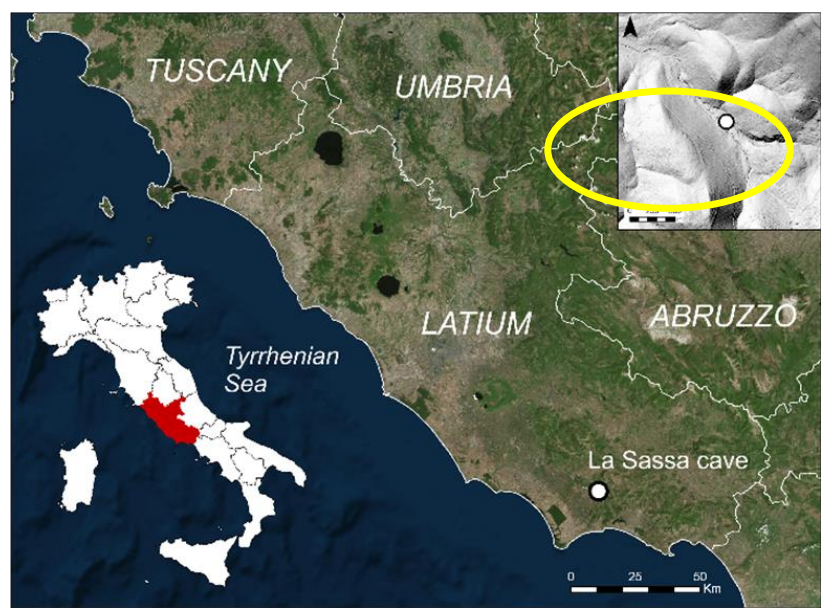

Figure 1. The location of the La Sassa Cave. Main background, Aerial photo from Esri, Digital Globe, GeoEye, Earthstar Geographics, CNES/Airbus DS, USDA, USGS, AeroGRID, IGN, and the GIS User Community. DTM from LiDAR data, $1 \mathrm{~m}$ resolution, from Ministero dell'Ambiente e della Tutela del Territorio e del Mare

Starting from 2015, several excavation campaigns have been carried out, led by the University of Groningen and in collaboration with the Università di Roma Tor Vergata.

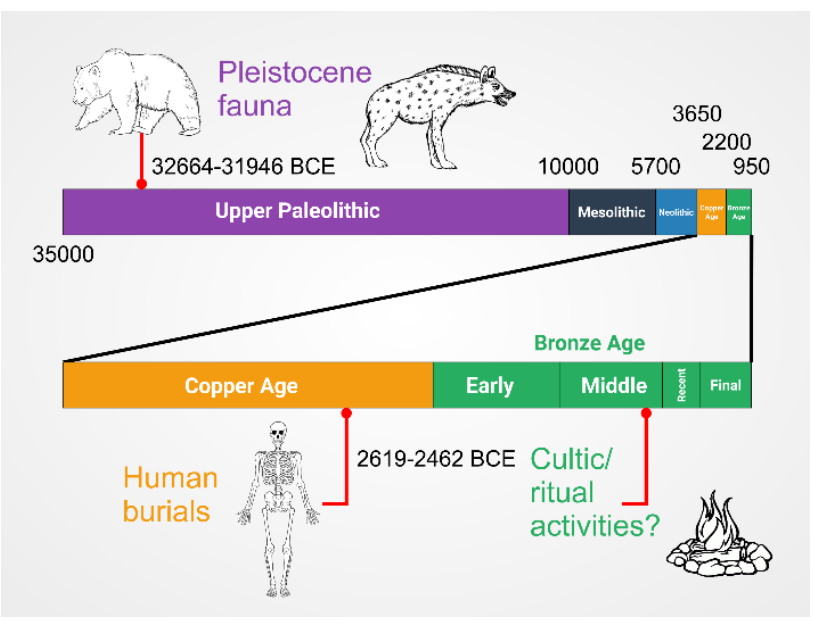

Figure 2. The simplified chronological sequence at La Sassa Cave, with radiocarbon calibrated dates (BCE) and conventional absolute chronology.
The excavations revealed a very complex stratigraphy which can be summarized as follows (from the bottom, figure 2): Pleistocene paleo surfaces which have been used as dens by Crocuta sp. (hyena) and Ursus arctos (brown bear, GrA-64830, $30210 \pm 180 \mathrm{BP}, 32664-31946 \mathrm{calBC}$ at $95.4 \%$, OxCal v. 4.3, IntCal13, on a humerus), hundreds of stacked human bones radiocarbon dated to the Copper Age (GrA-64828, 4000 $\pm 35 \mathrm{BP}$, 2619-2462 calBC at 95.4\%, OxCal v. 4.3, IntCal13, on a femur), and a very large quantity of Middle Bronze Age (MBA) impasto potsherds which might be interpreted as the remains of some cultic/ritual activities, as it is the case in some other contemporary caves (Cazzella and Guidi, 2016; Rosini, 2007; Silvestri et al. 2018).

The western part of the biggest chamber (figure 3, Room 1) was partially filled by a huge historical rock debris which covered the pre-protohistorical layers. Finally, the cave has been used as a shelter by the local population, during the World War II However, our data clearly indicates that the morphology of the cave has changed a lot, especially in the inner parts. In particular, the small lateral branch where the bear bones have been found (figure 3, sounding 6) appears too narrow for macromammals. Besides, the current entrance of the cave is a vertical shaft which is clearly unsuitable for hyenas and bears (figure 4).

In 2016 we noted that in sounding $\mathrm{N}$ (figure 3), some modern stone steps were clearly covered by some soil coming from a big niche in the northern wall which, at that time, was completely filled by rock and soil. That would indicate that, until recently, the niche was at least partially open to the outside.

During the 2018 excavation, in the same sector, we were able to identify some MBA layers with several human bones which possibly originates from the same niche.

Therefore, if our interpretation of the niche as the old entrance of the cave was correct, we needed to find the other side of the tunnel/branch. To estimate the best spot to start a test pit, we decided to perform a three-dimensional scan of both the cave and the ground in the immediate vicinity.

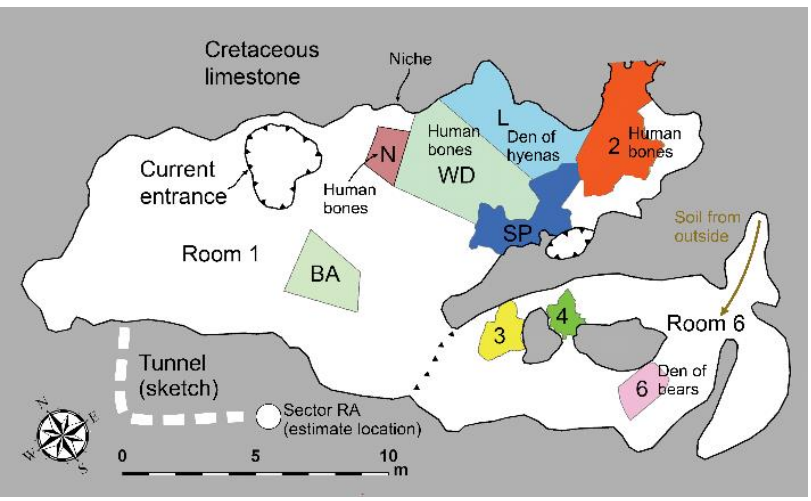

Figure 3. The map of the La Sassa cave with the soundings 


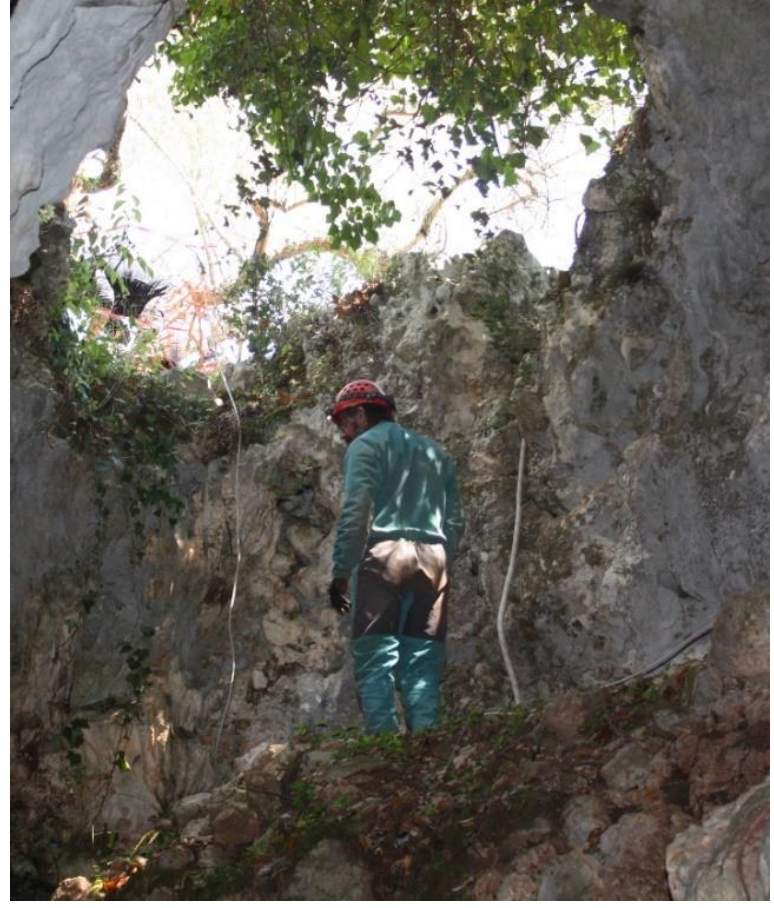

Figure 4. The current entrance of the cave

\subsection{GNSS setup}

In order to georeference the 3D model generated by the SfM procedure, it is necessary that at least three Ground Control Points (GCP) belonging to the same point cloud are known in the global reference system. This allows a 3D Helmert transformation. Three GCPs outside the cavity were stationed with tripods, the antenna of a Topcon Legacy-E doublefrequency GNSS receiver was then placed. Such antenna, being clearly visible, allowed easy collimation with the images taken by the camera used for the photogrammetric survey (figure 5). The data acquired by the GNSS receiver, which have stationed for about 40 minutes on each of the three points, were processed in post-processing mode using the data from the Fondi permanent station (FOND) managed by the Lazio Region and framed in the ETRF2000- RDN2008 (EPSG: 7792). The resulting baselines were about $13 \mathrm{~km}$ long.

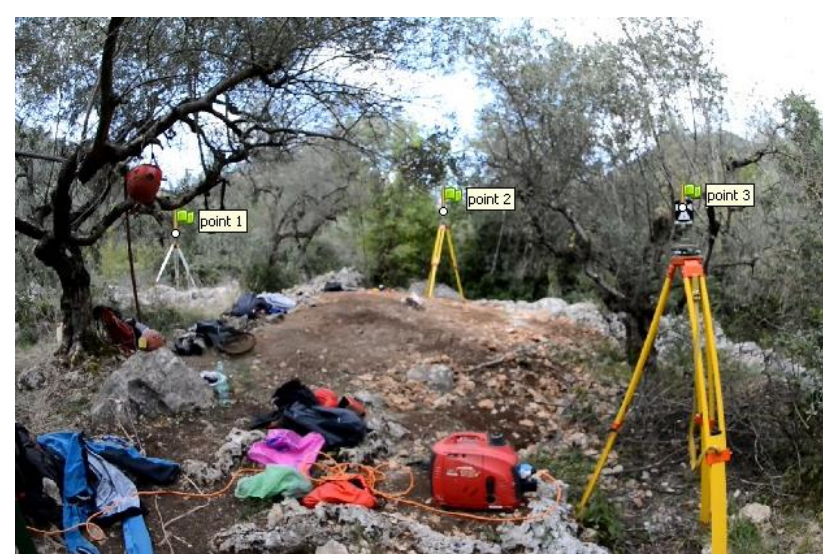

Figure 5. Collimation of GCPs on the images.

The heights of the antennas and accordingly of the point cloud are referred to the geoid, the transformation from the ellipsoidal heights was performed using the geoid model ITALGEO2005.

\subsection{Photogrammetric setup}

A full-frame DSLR camera Nikon D800E with a Nikkor $16 \mathrm{~mm}$ fisheye lens pre-calibrated was used for the photogrammetric survey. Fisheye lens provides a diagonal FOV of almost $180^{\circ}$. As mentioned before, the choice of the fisheye lens allows large overlap between two consecutive frames. The camera was set in video mode and the recording was performed in standard HD (High Definition) 1080p at $25 \mathrm{fps}$ (frame per second). Such camera settings allow to obtain an 18.7 microns pixel size on the sensor. The chosen camera settings allow us to work in the lowlight conditions of the cave.

2.3.1 Camera calibration: The camera calibration procedure is a fundamental task in the photogrammetric workflow. The purpose of such process is to determine the parameters of the interior orientation of the camera. Of course, the mathematical model chosen for the couple camera-lens is the starting point of the resolution procedure. In this work, the chosen model for the camera is the classical Brown model (Brown, 1971), which is composed by classical internal orientation parameters (principal distance, coordinates of the principal point, pixel size) extended by including the additional parameters that model the image distortion effects.

In close-range photogrammetry, the well-known self-calibration method (Fraser, 1997) is widely used to determine the camera calibration parameters. Specifically, this technique allows determining the interior orientation parameters from several images within a self-calibration bundle adjustment. Generally, the procedure is performed on a 3D test-field where the coordinates need to not be known, since they will be estimated by the bundle adjustment. The calibration is referred to as selfcalibration "on the job" process if it is performed directly during the survey operations (Lhuman et al., 2007). Strictly, the abovementioned procedures require specific geometric camera configurations to yield reliable results. For example: the photos should be taken convergent, pointing towards the test-field centre; each image should be acquired rotating the camera 90 degrees around the view direction; the test-field points should cover the sensor area to the greatest extent possible; finally, the interior orientation has to be fixed (e.g. no zooming). On the other hand, the test-field should have a 3D structure. All these technical practices assure reliable results, in terms of the principal distance precision, the decorrelation between distortion coefficients, the accuracy of distortion coefficient estimation and the stability of all internal parameters, respectively (Fraser, 2013).

These aforementioned precautions are easy to carry out before the survey in a controlled environment, such as a laboratory. Indeed, the network camera geometry could not be suitable for a self-calibration in a specific survey, especially in a cave environment where the spaces are not so large; on the other hand, the stability of camera parameters is affected by temperature and humidity.

These physical parameters can consistently change, especially in hypogeum environments: consequently, the self-calibration solution performed in the laboratory can become inaccurate. In this case, the obtained results are characterized by low accuracy and reliability (Nocerino et al., 2014).

The methodology proposed in this work is a joint processing approach between the classical self-calibration and the "on the job" one. Specifically, the camera was pre-calibrated in the laboratory, in order to easily perform the best practice abovementioned. Afterwards, the calibration parameters are refined during the processing stage of the images captured in the survey.

For this work, a camera equipped with a fisheye lens was used (figure 6). This lens utilises a different optical design that departs 
from the central perspective imaging model to produce an image circle up to $180^{\circ}$. If the image format sensor is larger than the resultant image circle, the camera is termed as fisheye system. Conversely, if the format is smaller than the image circle, such that the image diagonal covers about $180^{\circ}$ of the field of view, a quasi-fisheye system is attained.

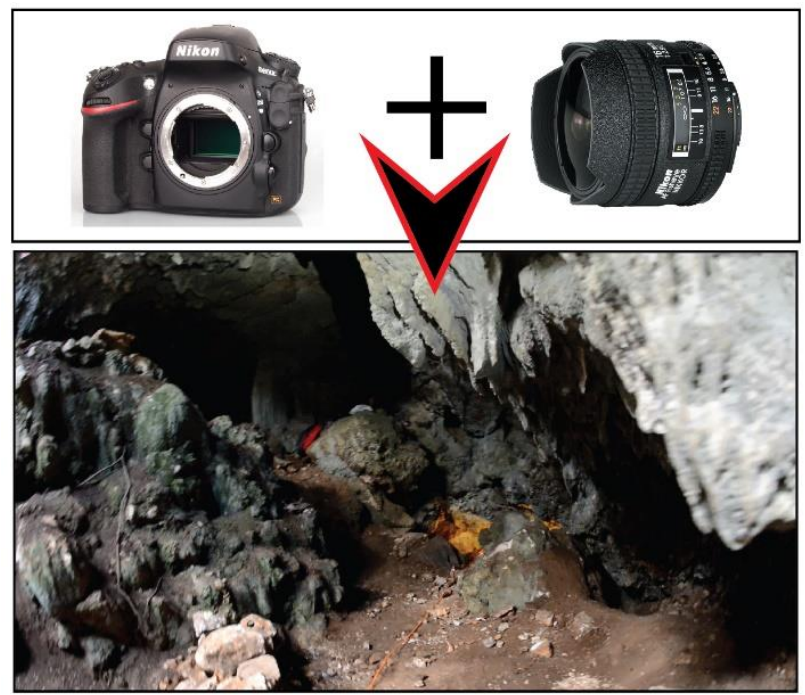

Figure 6. On the top is shown the Nikon D800E and fisheyes lens used: Nikkor $16 \mathrm{~mm}$, on the bottom a generic frame recorded during the survey.

For fisheye lens, the central perspective mapping is replaced by another model characterized by a stereographic, equidistant, orthogonal and orthographic projection (Forstener \& Wrobel, 2016).

Usually, when modelling the distortions in a fisheye lens with a conventional approach, the obtained solutions are mathematically unstable. Specifically, on the peripheral region of the image sensor, the gradient of the distortion curve is particular high describing the departure from the central perspective case (Lhuman et al., 2014). The lens employed for the survey are a quasi-fisheye, therefore the peripheral portion of image circle is not recorded on the sensor and the fisheye distortions can be modelled using the conventional perspective camera model and its classical radial distortion coefficients. Such model is more flexible than the fisheye model, because it can be exported in any photogrammetric software as well as integrated in any Structure from Motion algorithm. The figure 7 shows the plot of the radial distortion of the refined camera model obtained as output of the self-calibration process "on the job". In the table 1, the internal camera parameters obtained from the pre-calibration procedure and self-calibration "on the job" are reported.

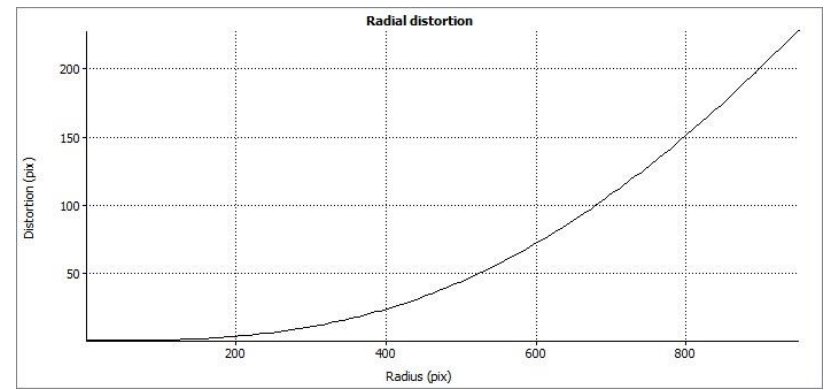

Figure 7. Radial distortion curve of fisheye lens.

Table 1. Comparison of Camera Calibration Parameters, between preliminary and refined calibration

\begin{tabular}{|c|c|c|}
\hline $\begin{array}{c}\text { Camera Model } \\
\text { [Units in Pixel] }\end{array}$ & Preliminary & Refined \\
\hline Focal & 923.95 & 914.6613 \\
\hline Principal Point $(d X, d Y)$ & $-16.6,1.2$ & $-3.5,17.6$ \\
\hline$K 1$ & -0.3242916 & -0.320706 \\
\hline$K 2$ & 0.1219527 & 0.116068 \\
\hline$K 3$ & -0.028444459 & -0.025265 \\
\hline
\end{tabular}

2.3.2 Acquisition phase: Before starting the acquisition phase, several targets were placed on the scene. Precisely: three outside the cave, on the vertical of the GNSS antennas; the others into the cave in order to strengthen the camera network and to control the solution. The camera was set in video mode in order to obtain a redundant number of images and to simultaneously enlarge the pixel size on the sensor (very useful in dark environments).

The acquisition phase started outside with the aim of acquiring the three GCP targets (figure 5). Afterwards, the camera operator slowly moved into the cave. The transition between the very bright environment (open-air) and the dark location (cave) was gradually performed. The camera focus was set to infinite, and the aperture was set to maximum. The sensitivity of the digital image system ISO automatically changed, to adjust the great bright gradient.

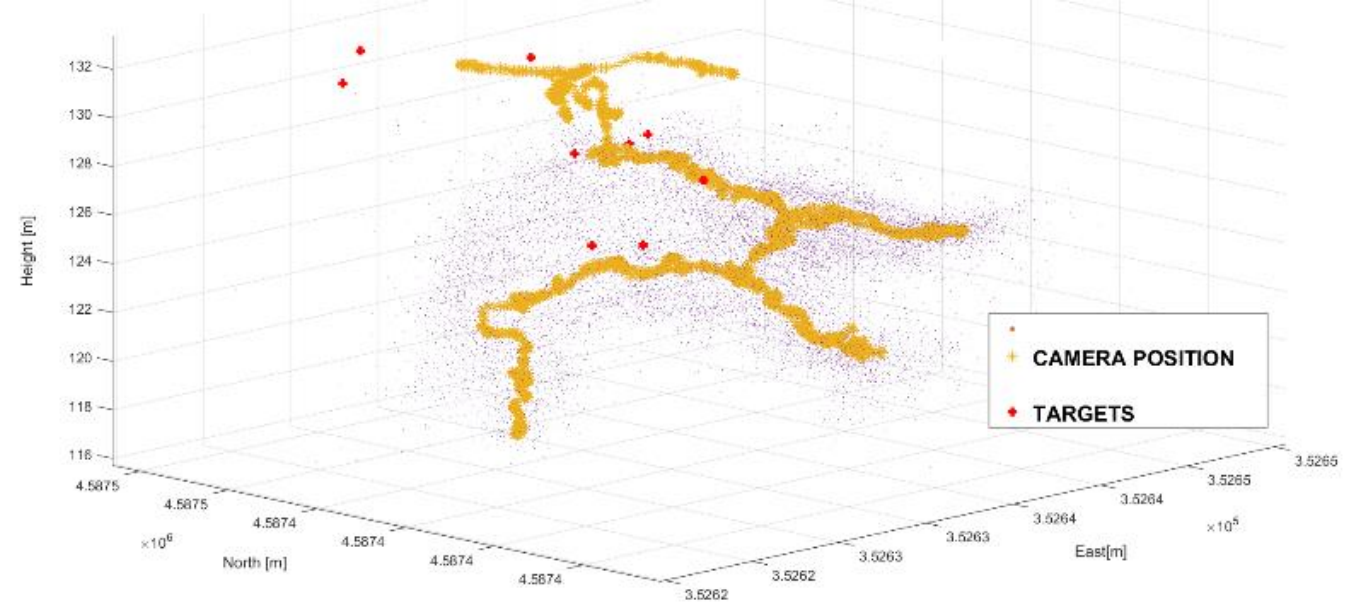

Figure 8 - Path followed by the operator during the survey 
In the cave there were no regular paths and the terrain was highly irregular. The camera operator recorded a series of short-length videos, like a stop and go topographic survey, because of the presence of high and steep slopes which suggested to proceed with caution. Two operators placed several light sources during the pauses, in order to obtain a uniform lighting of the scenario. Sundry steps have been taken to improve the video: the light source was never located in front of the camera or within the scene; no person or moving object were filmed, except in some parts of video where the shadow of the camera operator can be seen (figure 8).

\section{ELABORATION AND RESULTS}

The image orientation phase is a central step of the photogrammetry elaboration, indeed the quality of the result, in terms of accuracy and reliability, mainly depends on this step. The elaboration process can be divided in three main steps:

1. Image Orientation involves reconstructing the orientation parameters of all camera stations at the capturing time. The result is a photogrammetric model composed by both 3D positions and orientations of camera stations and 3D tie-points cloud. Arbitrary scale and reference system are set;

2. Scaling and Georeferencing. In this step the photogrammetric model is adjusted and georeferenced using a set of GCPs;

3. Dense Points Cloud Generation is the last step. It performs a densification of the sparse points cloud obtained in the first step.

\subsection{Image orientation}

About 15 video tiles were acquired and processed during the survey operations. A sequence of images was extracted from each tile by sampling one frame every ten; the extraction procedure provided 3899 images. The image orientation process was performed in a unique project, using the image-based modelling software Agisoft Photoscan. The software was able to find the external orientation of all frames, producing a sparse points cloud of 524,168 points. The followed procedure is fully automatic and is based on an automatic tie-point extractor algorithm, known as blob detector. The latter provides highly distinctive features invariant to image scaling and rotation, and partial invariant to brightness (Lowe, 1999; Bay et al., 2006). Especially in this specific environment, the blob detector is very important to preserve the multiplicity of the tie-points. Furthermore, they provide a reliable solution for managing thousands of images in a reasonable time. Subsequently, a bundle adjustment in free network was carried out, in order to estimate the camera poses and the 3D positions of the tie-points. The project was oriented using internal camera parameters computed during the calibration task, providing a reprojection total error of 1.6 pixels.

\subsection{Scaling and Georeferencing}

In order to achieve the goal of this work, the photogrammetric model needed to be georeferenced using at least 3 GCPs (Ground Control Point), that were recorded at the beginning (figure 5, see also paragraph 2.2). Further targets were located in the scene in order to estimate the deformation of the model. Such operation was performed rerunning the Bundle Block Adjustment algorithm in minimal constrain mode. Troughout this process, the camera parameters were unlocked in order to be adjusted according to the self-calibration "on the job" procedure. The total error reported on the GCPs is about 0.1 meters, more than enough for the purpose of this work.

\subsection{Dense cloud generation}

To provide an accurate 3D model and to evaluate the surface of the cave in terms of morphology and topography, a dense points cloud was obtained. The image matching algorithm worked with an image downscaled to $25 \%$, generating a cloud of $6,910,198$ points (figure 9).

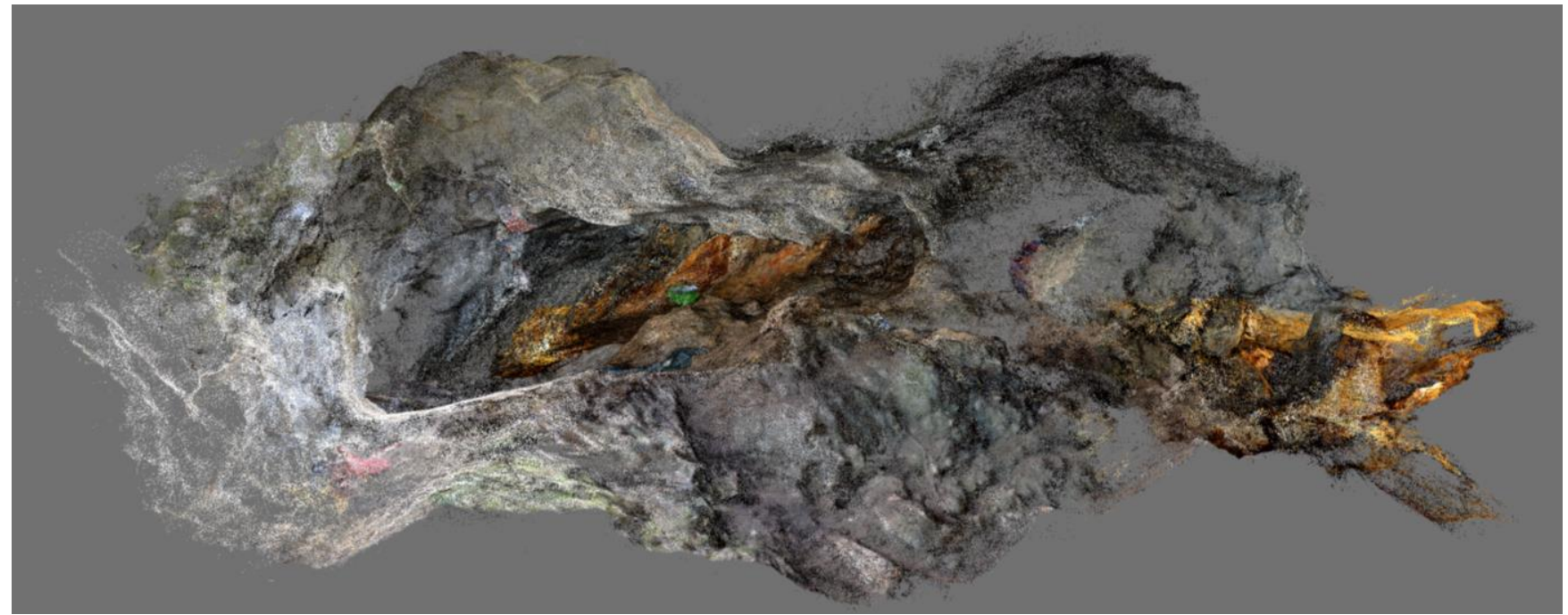

Figure 9 - Dense Points Cloud obtained after the image matching processing

\subsection{Results Analysis}

The main goal of this work was to obtain a 3D model of the cave, in order to help the archaeologists and speleologists in the search for the ancient entrances and rooms. In this way, the specialists were able to start the new excavation with a high probability of success. Of course, the morphological results are also very important to obtain high quality records of the environment and can serve as a basis for further (and different kind of) research. For these reasons, we had to estimate the 3D model, in order to highlight any deformation. 
3.4.1 Morphologic results: The morphological approach allows to inspect the surface of the cave and consequently to determine possible passages. Specifically, such approach was used to detect the ancient entrance used by the Pleistocene hyena(s) and later by the humans, in the Copper Age. Indeed, a possible passage was detected in a specific point of the cave, although at that moment it was completely obstructed by stones and soil. The archaeologists supposed and detected a point outside the cave as the correspondent possible entrance. The 3D survey confirmed this hypothesis: figure 10 and 11 showed that the outside excavation was compatible with the inside candidate entrance (figure 10 and figure 11).

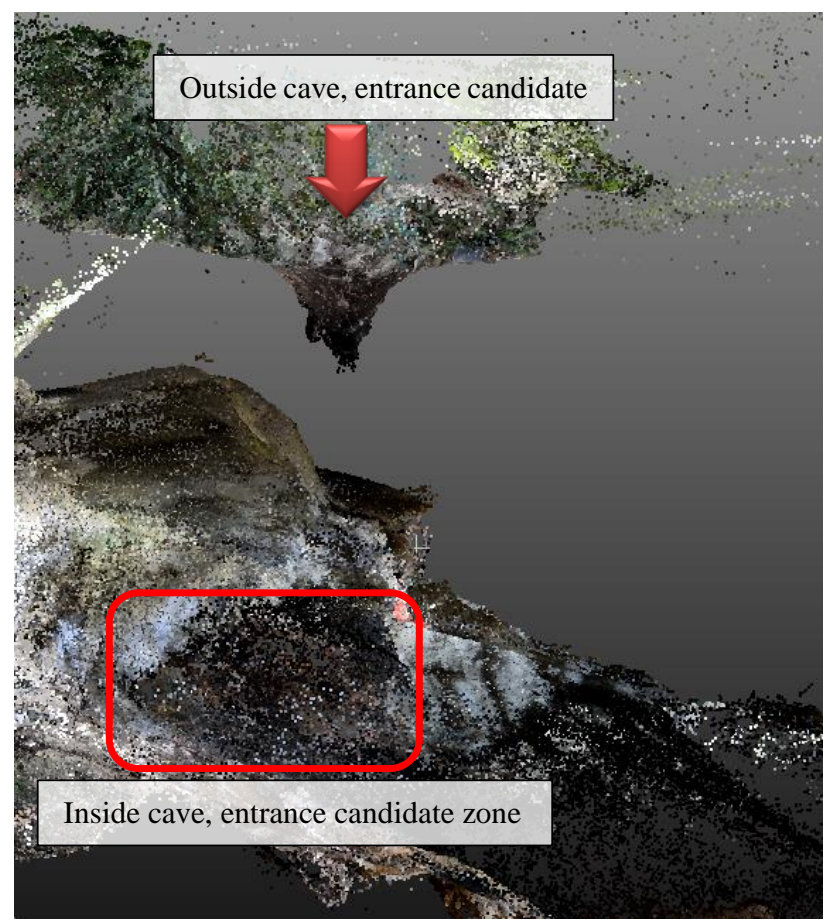

Figure 10 - Section of Dense Points Cloud, used to determine the position of the human-hyena entrance

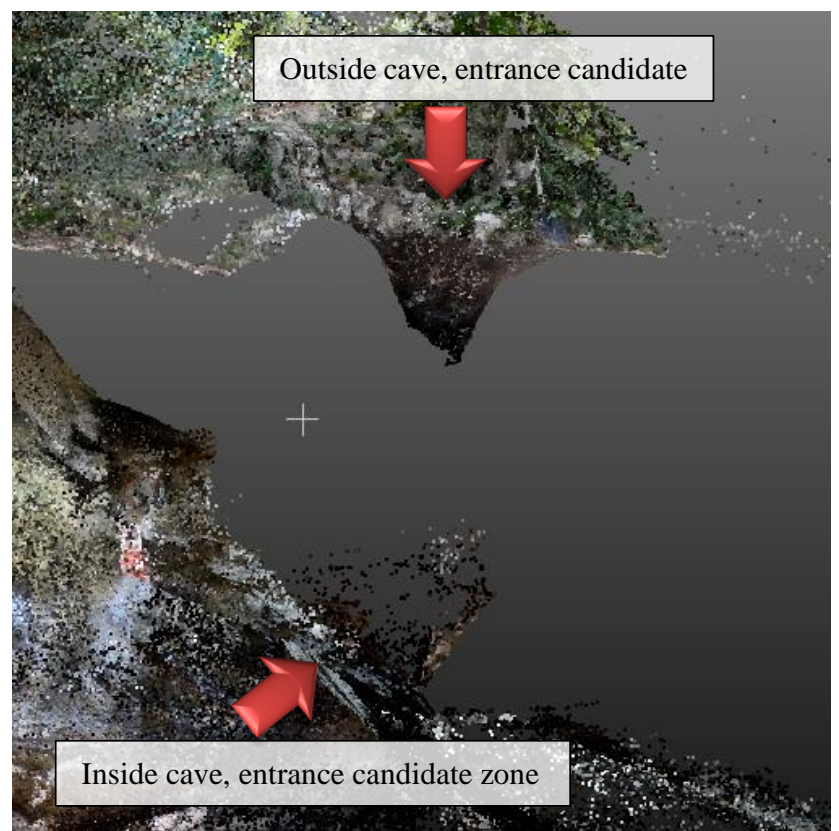

Figure 11. After this result, a deeper test pit definitely confirmed the hypothesis
3.4.2 Error analysis: The survey operations were carried out filming during the cave descent and ascent of the operator. Along the path, several targets were acquired to estimate the precision of the model. Three targets were then chosen as check points. This approach has been developed in order to estimate the reliability of the 3D model. It is based on the comparison between the 3D coordinates of the same target on the way and back. Specifically, the same target is labelled with two different names: one label is assigned in all images acquired during the descent into the cave; the other is assigned in all frames recorded on the way back.

The software computes the same target using two different datasets of images: the obtained results (reported in table 2) provide an estimation of the cloud points precision.

Table 2. Comparison of targets 3D coordinates, all values are expressed in metres

\begin{tabular}{|c|c|c|c|c|}
\hline Target Id & $\Delta \mathrm{X}$ & $\Delta \mathrm{Y}$ & $\Delta \mathrm{Z}$ & Total \\
\hline $6(66)$ & $-0,012$ & $-0,041$ & 0,001 & 0,042 \\
\hline $7(77)$ & $-0,031$ & $-0,021$ & $-0,003$ & 0,037 \\
\hline $8(88)$ & 0,018 & 0,000 & 0,019 & 0,026 \\
\hline Mean & $-0,008$ & $-0,020$ & 0,005 & 0,035 \\
\hline
\end{tabular}

\section{CONCLUSIONS AND FUTURE WORKS}

Through the observation of the 3D scan of both the cave and the soil surface it was possible to estimate the position of the ancient outside access to the Room 1. At the end of 2018, we carried out a small test pit which confirmed the hypothesis.

At the moment, the complete excavation of the ancient tunnel is planned for the 2019 campaign. However, we already observed the presence, up to a considerable depth, of contemporary finds which indicates that the entrance has been completely closed only recently. A possible explanation involves the local shepherds who use to fill all the holes in the ground with stones and rocks, to prevent sheep injuries.

Nevertheless, despite it is highly probable that this entrance was used by hyena and later by humans, it is less clear if the bears could have reached their dens from Room 1.

Actually, just west of the sounding 6, there is a (now) narrow and quite steep tunnel which is pointing upwards. The walls and the ceiling of the latter are entirely covered by concretions, which means that the tunnel was originally larger. Moreover, we have been able to collect few dog bones in a small test pit at the bottom of the tunnel, which was completely covered by soil clearly coming from outside. In the light of those data we hypothesize that the tunnel could have been the second ancient entrance to the cave, perhaps large enough for a bear.

The limited dimensions of these portions of the cave (the ceiling is around $60 \mathrm{~cm}$ high) prevented their mapping with the total station and the usual equipment. We were then forced to use a classical speleological technique, with the aid of a geological compass, a clinometer and an electronic distance metres, which resulted in a very inaccurate map.

Besides, in the 2018 campaign, some speleologists belonging to the Shaka Zulu Club Subiaco found a new unexplored tunnel in the south-western part of the cave, around 20m deep from the current entrance. The tunnel is very narrow and in some places the ceiling is only $40 \mathrm{~cm}$ high (figure 12). Inside, several fragments of so-called flask-shaped jars (vasi a fiasco) were recovered, together with a pyx lid still partially englobed in a stalagmite (figure 13). These vessels are typical grave goods belonging to the Copper Age Gaudo Culture (Anzidei et al., 2011; Anzidei and Carboni, 2006; Carboni, 2002). The tunnel ends in a very small room (sector RA), where we found a $1 / 2$ years baby burial belonging to Copper Age, together with some 
grave goods and fauna remains. Here again, the very limited dimension of the tunnel prevents its precise mapping.

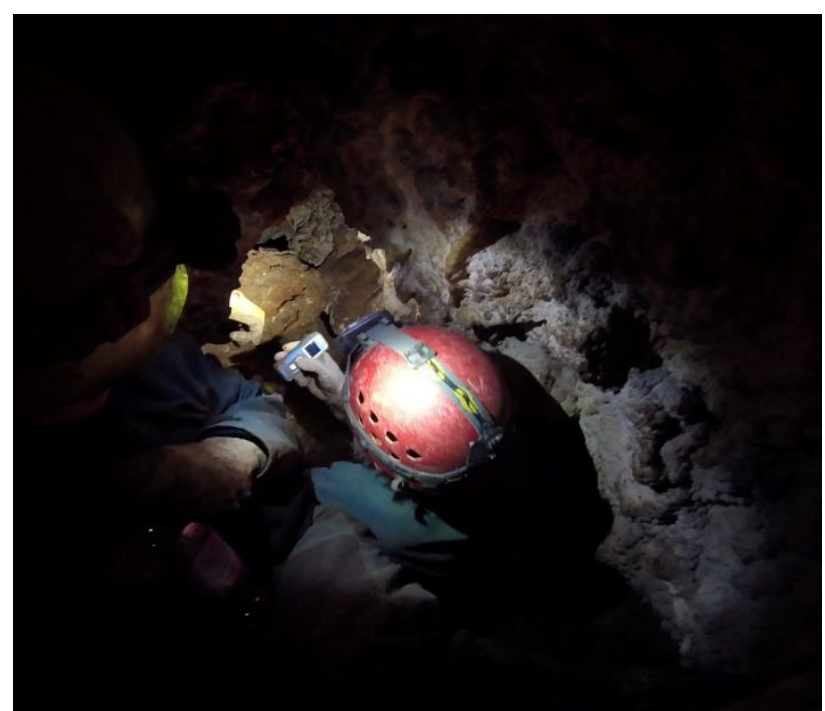

Figure 12 - The entrance of the new unexplored tunnel (photo A. Ferracci)

For the future we intend to use the same technique we employed successfully in finding the ancient entrance of Room 1, both in the inner portion of the cave (sounding 6) and in the new tunnel. From an archaeological point of view, this technique has proved to be extremely valuable for its rapidity and precision. Moreover, in certain specific cases, like the ones we just mentioned, it is the only technique that can be performed with such a small equipment.

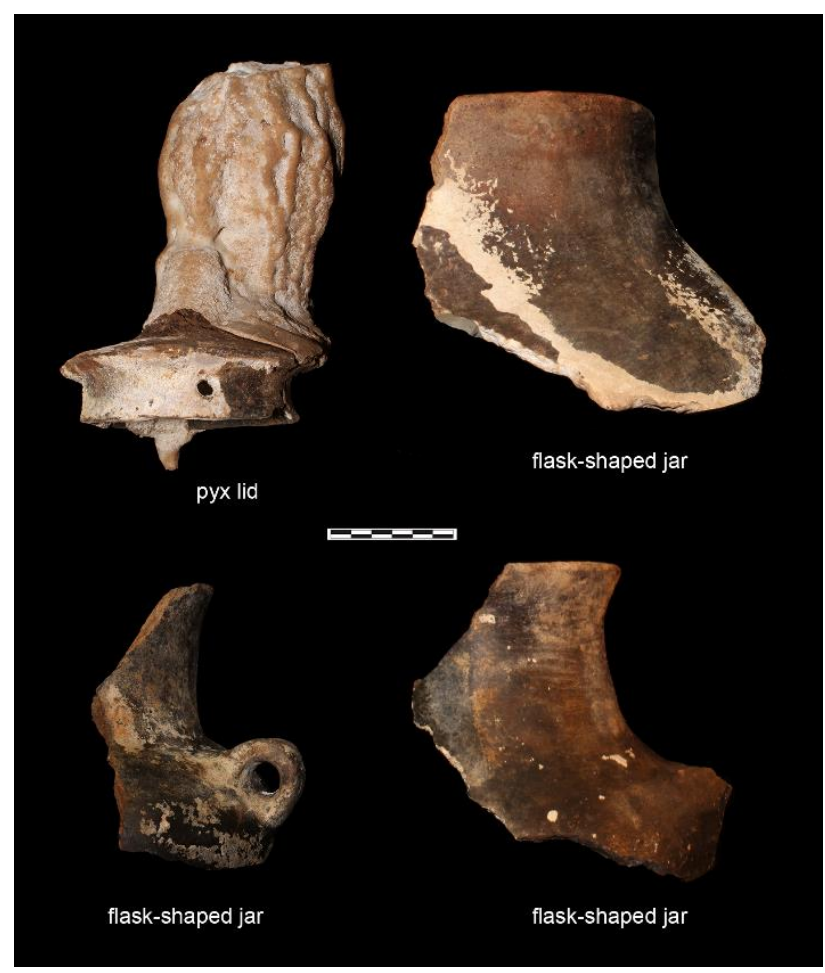

Figure 13 - The Copper Age fragments collected in the new tunnel (photo A. Ferracci)

\section{REFERENCES}

Alessandri, L., Rolfo, M.F., 2015. L'utilizzo delle cavità naturali nella media età del Bronzo: nuovi dati dal Lazio meridionale. Boll. Unione Stor. e Arte 10, 109-126.

Anzidei, A.P., Carboni, G., 2006. Rinaldone e Gaudo in un territorio di confine: il Lazio centro-meridionale, in: Atti Del VII Incontro Di Studi Preistoria e Protostoria in Etruria. Pastori e Guerrieri Nell'Etruria Del IV e III Millennio a.C. La Civiltá Di Rinaldone a 100 Anni Dalle Prime Scoperte. pp. 174-192.

Anzidei, A.P., Carboni, G., Carboni, L., Catalano, P., Celant, A., Cereghino, R., Cerilli, E., Guerrini, S., Lemorini, C., Mieli, G., Musco, S., Rambelli, C., Pizzuti, F., 2011. Il Gaudo a sud del Tevere: abitati e necropoli dall'area romana, in: Atti Della XLIII Riunione Scientifica Dell'Istituto Italiano Di Preistoria e Protostoria: L'età Del Rame in Italia. pp. 309-321.

Bay, H., Tuytelaars, T., \& Van Gool, L., 2006. Surf: Speeded up robust features. In Computer vision-ECCV 2006 (pp. 404-417). Springer Berlin Heidelberg.

Biber, P., Andreasson, H., Duckett, T., \& Schilling, A., 2004. 3D modeling of indoor environments by a mobile robot with a laser scanner and panoramic camera. In Intelligent Robots and Systems, 2004.(IROS 2004). Proceedings. 2004 IEEE/RSJ International Conference on (Vol. 4, pp. 3430-3435). IEEE.

Brown, D.C., 1971. Close-range camera calibration. PE\&RS, Vol. 37(8), pp.855-866.

Carboni, G., 2002. Territorio aperto o di frontiera? Nuove prospettive di ricerca per lo studio della distribuzione spaziale delle facies del Gaudo e di Rinaldone nel Lazio centromeridionale. Origini XXIV, 235-299.

Cazzella, A., Guidi, A., 2016. Aspetti simbolici connessi con le grotte nell'Italia centro-meridionale dal Neolitico alla prima età del ferro. Quad. di Stud. e Mater. di Stor. delle Relig. supp. 82, 47-63.

Cole, D. M., \& Newman, P., M. 2006: Using laser range data for 3D SLAM in outdoor environments. In Robotics and Automation, 2006. ICRA 2006. Proceedings 2006 IEEE International Conference on (pp. 1556-1563). IEEE.

Del Pizzo, S., Troisi, S., 2011. Automatic orientation of image sequences in cultural heritage. nternational Archives of the Photogrammetry, Remote Sensing and Spatial Information Sciences - ISPRS Archives 38(5W16), pp. 293-300

Förstner, W., \& Wrobel, B. P. 2016. Photogrammetric computer vision. Springer International Publishing Switzerland.

Fraser, C. S., 1997. Digital camera self-calibration. ISPRS Journal of Photogrammetry and Remote sensing, 52(4), 149-159.

Fraser, C. S. 2013. Automatic camera calibration in close range photogrammetry. Photogrammetric Engineering \& Remote Sensing, 79(4), 381-388.

Gallay M, Kanuk J, Hochmuth Z, Meneely J.D, Hofierka J \&Sedlak V 2015. Large-scale and high-resolution 3-D cave mapping by terrestrial laser scanning: a case study of the Domica Cave, Slovakia, International Journal of Speleology, 277-291 
Jordan, Joseph H., 2017. Modeling Ozark Caves with Structurefrom-Motion Photogrammetry: An Assessment of Stand-Alone Photogrammetry for 3-Dimensional Cave Survey" (2017).Theses and Dissertations. 2406. http://scholarworks.uark.edu/etd/2406

Lowe, D. G., 1999. Object recognition from local scale-invariant features. In Computer vision. The proceedings of the seventh IEEE international conference on (Vol. 2, pp. 1150-1157).

Luhmann, T., Robson, S., Kyle, S., \& Boehm, J., 2014. Closerange photogrammetry and 3D imaging. Walter de Gruyter.

Luhmann, T., Robson, S., Kyle, S., \& Harley, I., 2007. Close range photogrammetry. Wiley.

Menna, F., Nocerino, E., Troisi, S., Remondino, F., 2015. Joint alignment of underwater and above-the-water photogrammetric 3D models by independent models adjustment. International Archives of the Photogrammetry, Remote Sensing and Spatial Information Sciences - ISPRS Archives 40(5W5), pp. 143-151 DOI: 10.5194/isprsarchives-XL-5-W5-143-2015

Nocerino, E., Menna, F., \& Remondino, F., 2014. Accuracy of typical photogrammetric networks in cultural heritage $3 \mathrm{D}$ modeling projects. The International Archives of Photogrammetry, Remote Sensing and Spatial Information Sciences, 40(5), 465.

Mouragnon, E., Lhuillier, M., Dhome, M., Dekeyser, F., \& Sayd, P, 2009: Generic and real-time structure from motion using local bundle adjustment. Image and Vision Computing, 27(8), 11781193.

Perfetti, L., Polari, C., Fassi, F., 2017. Fisheye photogrammetry: Tests and methodologies for the survey of narrow spaces. International Archives of the Photogrammetry, Remote Sensing and Spatial Information Sciences - ISPRS Archives 42(2W3), pp. 639-644 DOI: 10.5194/isprs-archives- XLII-2-W3-573-2017

Rosini, L., 2007. I materiali della Grotta Vittorio Vecchi (Sezze, LT), in: Atti Della XL Riunione Scientifica Dell'Istituto Italiano Di Preistoria e Protostoria, Strategie Di Insediamento Fra Lazio e Campania in Età Preistorica e Protostorica. pp. 695-703.

Silvestri L., Rolfo M.F., Angle M., Skeates R., Salari L., Faunal Remains and Ritualisation 2018. Case Studies from Bronze Age Caves in Central Italy. In Livarda A., Madgwick R., Riera Mora S., (Eds), The Bioarchaeology of Ritual and Religion, Oxford, Philadelphia, Oxbow Books, 129-147, ISBN 978-1-78570-8282.

Thrun, S., 2002. Robotic mapping: A survey. Exploring artificial intelligence in the new millennium, 1, 1-35.

Troisi, S., Del Pizzo, S., Gaglione, S., Miccio, A., Testa, R.L., 2015. 3D models comparison of complex shell in underwater and dry environments. International Archives of the Photogrammetry, Remote Sensing and Spatial Information Sciences - ISPRS Archives 40(5W5), pp. 215-222

DOI: 10.5194/isprsarchives-XL-5-W5-215-2015

Troisi, S., Baiocchi, V., Del Pizzo, S., Giannone, F., 2017. A prompt methodology to georeference complex hypogea environments. International Archives of the Photogrammetry, Remote Sensing and Spatial Information Sciences - ISPRS
Archives 42(2W3), pp. 639-644 DOI: 10.5194/isprs-archivesXLII-2-W3-639-2017 